\title{
Editorial
}

\section{Special column for the memory of Professor CHEN Naixing}

The special column of Journal of Thermal Science (JTS) is dedicated to the late Professor CHEN Naixing, who passed away on the $6^{\text {th }}$ of August of 2018 when he was turning 85 years old. Professor Chen received his postgraduate degree from Bauman State Technical University in Moscow in 1958. Before he joined the Institute of Engineering Thermophysics of Chinese Academy of Sciences in 1980, he also worked for Harbin Turbine Factory, the Naval Research Center, and the Institute of Mechanics of Chinese Academy of Sciences.

Professor Chen had devoted all his working life to aerothermodynamics of turbomachinery and to promoting the engineering thermophysics discipline in China. He was an elected International Committee Member of Japan Gas Turbine Society. He also served as a board member of the Aerodynamics Divison of the Chinese Society of Engineering Thermophysics, the Power Division of the China Aviation Society, the Academic Degrees Committee of the Chinese Academy of Sciences, the Review Committee of the National Natural Science Foundation of China, the Editorial Board of Journal of Engineering Thermophysics (in Chinese), Chinese Science, and Chinese Science Bulletin. He was a Guest Professor at the University of Science and Technology of China and Harbin Institute of Technology.

He was awarded the second class prize of Natural Science Award of Chinese Academy of Sciences in 1989 for his achievements on "Basic equations of viscous flow and its applications in aerodynamic simulation of turbomachinery". He also received the second class prize of National Natural Science Award in 2002 for his outstanding achievements in the fields of turbomachinery in forward and inverse problems and optimization design.

He authored the book of AEROTHERMODYNAMICS OF TURBOMACHINERY-Design and Analysis, which was published in 2010. He co-authored the book of Aerothermodynamics of Axial Flow Turbomachinery for Marine Gas Turbines (Principles, Design and Experiments) (in Chinese) with Professor LI Genshen and Professor QIANG Guofang, which was published in 1980. Both are significant works in the field of turbomachinery.

Professor Chen founded the series of "International Symposium on Experimental and Computational Aerothermodynamics of Internal Flows (ISAIF)" in 1989, which has become an important international conference in the turbomachinery community. Especially, he was also the founder-editor of Journal of Thermal Science, which has been an international SCI-indexed journal in the energy and power system fields, and has achieved significant progress recently.

As the only individual participant from China, he participated in the blind test competition of the performance prediction for a single compressor rotor organized by ASME in 1994. His numerical simulation code was regarded as one of the top ten valid programs internationally.

This special column of Journal of Thermal Science (JTS) includes seven invited technical papers, contributed by Professor Chen's students and colleagues from prestigious universities and research institutes in China, covering the subjects of adjoint-based aerodynamic optimization, robust blade design methods, stall warning approaches, endwall film cooling, loss mechanism of casing treatment and loss characteristics in a low-pressure turbine linear cascade. Liu et al. proposed a stall warning method using fast wavelet analysis to realize the prediction of two types of rotating stall inception in two low-speed axial compressors. Su et al. proposed a method to compute for the sensitivities of the geometric constraints on the blade thicknesses, and verified the effectiveness of the method to treat geometric constraints in adjoint optimization. Xu et al. validated the efficacy of an acoustic-theory based stall warning approach to detect the perturbations of compressors and successfully applied this approach with SPS casing treatment to extend the operating range of a two-stage compressor. Gao et al. built a robust design method considering profile error and investigated the influence of profile error uncertainty on aerodynamic performance of the compressor blades. Cui et al. presented a numerical study on the aerodynamics loss 
reduction characteristics after the leading-edge (LE) optimization in a low-pressure turbine linear cascade. Du et al. explored the impacts of the trenched film holes coolant flow upon the endwall cooling characteristics and phantom cooling performance. Zhang et al. investigated the flow loss mechanism in a highly-loaded mixed-flow compressor with the axial-slot casing treatments by examining the distribution of entropy generation. This special column is no doubt a valuable representation of the-state-of-the-art of research in aerothermodynamics of turbomachinery.

As his students and colleagues, we are very grateful to have the opportunity to organize this special column to pay tribute to Professor CHEN Naixing. We believe that this is the best way to commemorate Prof. Chen's contributions, and to encourage young researchers to dedicate in the research and development of aerothermodynamics of turbomachinery. We also would like to thank all the reviewers and the authors for their hard work and great efforts in accomplishing this special column.

Guest Editors of the Special Column Prof. NIE Chaoqun E-mail: ncq@iet.cn

Prof. ZHANG Hongwu E-mail: zhw@iet.cn

Prof. DU Juan

E-mail: dujuan@iet.cn Institute of Engineering Thermophysics, Chinese Academy of Sciences, Beijing, China 